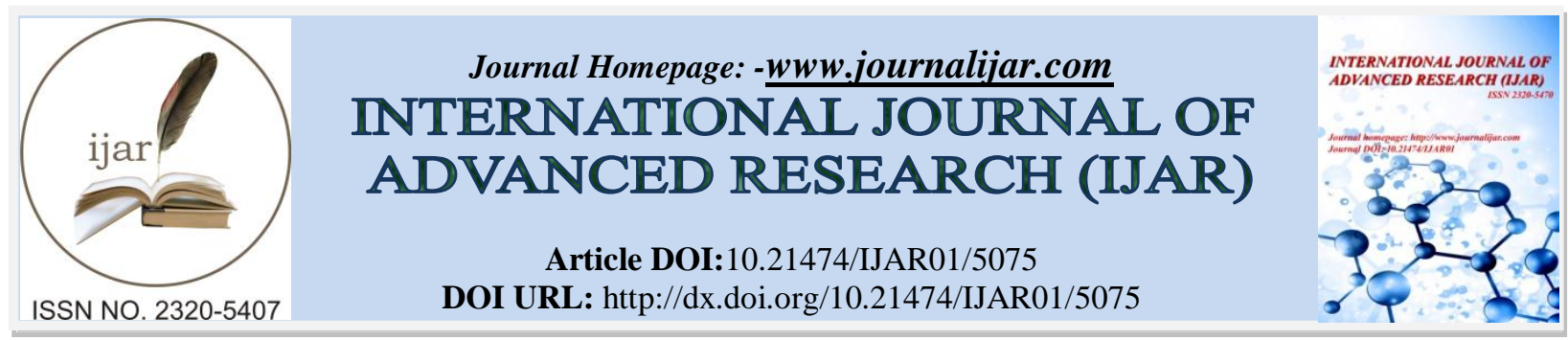

RESEARCH ARTICLE

\title{
PREVALENCE OF NOISE INDUCED HEARING LOSS AMONG POLICE PERSONNEL IN MADURAI CITY.
}

Dhinakaran. $\mathrm{N}^{\mathbf{1}}$ and Karthikeyan. B. $\mathrm{M}^{\mathbf{2}}$.

1. Professor \& HOD, Department of ENT, Madurai Medical College \& Government RAJAJI HOSPITAL, Madurai - 20.

2. SPEECH Therapist \& Audiologist, Department of ENT, Government Rajaji Hospital, Madurai - 20.

\section{Manuscript Info}

Manuscript History

Received: 05 June 2017

Final Accepted: 07 July 2017

Published: August 2017

Key words:-

Noise induced hearing loss, Pure Tone Audiometry, Pure Tone average, $4000 \mathrm{~Hz}$ threshold, years of service.

\section{Abstract}

Noise induced hearing loss (NIHL) is one of the common cause of sensorineural hearing loss, which is well documented among the industrial workers, but the same is not much noticed among the high risk overt group (i.e.) the Police personnel. The present study aimed at finding out the prevalence of NIHL among the police personnel in Madurai city who had more than 15 years of service in the police department. 241 police personnel with age more than 40 years, served as subjects for the present study. The subject group comprised with majority of males (219 males) and 22 females. All the subjects had undergone Pure Tone Audiometry testing in a sound proof room. The results showed that out of 241 subjects, 88 subjects had normal hearing sensitivity and 153 subjects had affected hearing (i.e.) $63.48 \%$ of the subjects had hearing loss. Hence, the subjects were divided into two groups, with Group 1 comprising 88 normal hearing individuals and Group 2 with 153 hearing loss population. The results were further statistically analyzed for the following variables: Pure Tone Average (Right \& Left ear), Threshold at $4000 \mathrm{~Hz}$ (Right ear and Left ear) and their years of service. The statistical analyses showed a significant increase in Pure Tone Average and $4 \mathrm{KHz}$ threshold in Group 2 than Group 1. Also, as the years of their service increased, their degree of hearing loss also increased. Hence the study concludes that even police personnel are at high risk for Noise Induced Hearing Loss due to their work environment and work nature. So, the police personnel are also advised to use Ear protective devices during their work hours and to undergo periodic auditory evaluations.

Copy Right, IJAR, 2017,. All rights reserved.

\section{Introduction:-}

Noise induced hearing loss (NIHL) is one of the most common problems seen among the individuals working in noisy environment. NIHL is a sensorineural hearing loss, which can be caused due to exposure to steady sound or intense impulse sounds, which may be occupational or non-occupational. The audiological findings of NIHL shows, sensorineural hearing loss component more in high frequency region (i.e.) between $3000 \mathrm{~Hz}$ to $6000 \mathrm{~Hz}$ with a dip at $4000 \mathrm{~Hz}$. Some findings also reported to have high frequency sloping loss patterns among NIHL individuals. The 
NIHL can cause temporary or permanent damage to cochlear hair cells. The damage caused by noise is determined by the intensity of sound and duration of sound exposure.

World Health Organization (WHO) estimated $1-1.6$ million DALY (Disability Adjusted Life Years) in western European countries, which is due to environmental noise from non-occupational sources such as traffic noise. The noise induced hearing loss is well identified in occupational conditions from industries or exposure to high noise levels (e.g. motor pumps, aircraft sound etc.), but it is not much documented among the individuals, where the noise exposure risk is not so overt, such as among police personnel. Many studies have been conducted to find the extent of NIHL among military personnel as they are more exposed to gunfire and other intense impulse sounds. Very few studies have been carried among police forces who are exposed to various noise factors such as vehicle horns, gunfire, barking from police dog, traffic noise, walkie talkie announcements etc. Especially for police motor cyclist and police car drivers, the noise exposure can range from $65 \mathrm{dBA}$ to $90 \mathrm{dBA}$ and upto $105 \mathrm{dBA}$ in open roads.

\section{Objective of the study:-}

In Madurai city, the police personnel of various units with age more than 40 years are required to undergo periodic medical examination annually. As a part of this examination, audiological evaluations will also be carried out. The current study aimed to find out the prevalence of Noise Induced Hearing Loss among the police personnel in Madurai city.

\section{Materials and Method:-}

The present study is cross-sectional and descriptive one, conducted at Government Rajaji Hospital, Madurai. An audiometric survey was carried out among 258 police personnel aged between 40 - 58 years. Prior to audiological evaluations, a detailed medical, personal and occupational history was taken. Detailed information on risk factors like smoking, alcohol consumptions, diabetes mellitus, acoustic trauma, ototoxic drugs and previous ear diseases were obtained from the subjects.

Based on otolaryngologist opinion and audiological findings, 17 subjects out of 258 subjects were found to have conductive hearing loss and they were excluded from the study. The remaining 241 subjects were included for the further study.

The subjects hearing levels were measured by using Pure Tone Audiometry (PTA) procedure. The audiometric evaluations included both air conduction and bone conduction assessments at $250 \mathrm{~Hz}, 500 \mathrm{~Hz}, 1000 \mathrm{~Hz}, 2000 \mathrm{~Hz}$, $4000 \mathrm{~Hz}$ and $8000 \mathrm{~Hz}$. The MAICO MA 52 pure tone audiometer was used for the present study. The audiological evaluations were carried out in an acoustic proof sound treated room setup. Thresholds were estimated for the above mentioned frequencies. The thresholds $>15 \mathrm{dBHL}$ was considered as hearing loss in any of the above mentioned frequencies. The audiograms with $4 \mathrm{KHz}$ dip in both air conduction and bone conduction are considered as NIHL. Based on Goodman's classification, hearing loss was then assessed: 0-15dBHL (Normal), 16-25dBHL (Minimal), 26-40dBHL(Mild), 41-55dBHL(Moderate), 55-70dBHL(Mod.severe), 71-90dBHL(severe) and above 90dBHL (Profound). The hearing loss levels in the current study were categorized by averaging the thresholds at frequencies $500 \mathrm{~Hz}, 1000 \mathrm{~Hz}, 2000 \mathrm{~Hz}$ and $4000 \mathrm{~Hz}$. Also, threshold at $4000 \mathrm{~Hz}$ was noted.

The audiometric evaluations showed that out of 241 subjects, 88 subjects found to have normal hearing sensitivity and remaining 153 subjects had various degrees of sensorineural hearing loss. Hence, the subjects were divided into two groups with Group 1 comprising of 88 normal hearing police personnel (76 males and 12 female subjects) and Group 2 with 153 individuals (143 males and 10 females) with hearing loss. The results of the audiometric evaluations were analyzed on the following variables: years of service, pure tone averages of Right ear and Left ear, threshold at $4 \mathrm{KHz}$ for Right and Left ears between both the groups

\section{Results:-}

The audiometric evaluation results were analyzed on the following variables: years of service, pure tone average (Right \& Left ear) and threshold at $4 \mathrm{KHz}$ (Right \& Left ear) between both the groups. A statistical comparison for the above mentioned variables were made between both the groups and the results are shown in Table 1 and Graph 1 . 


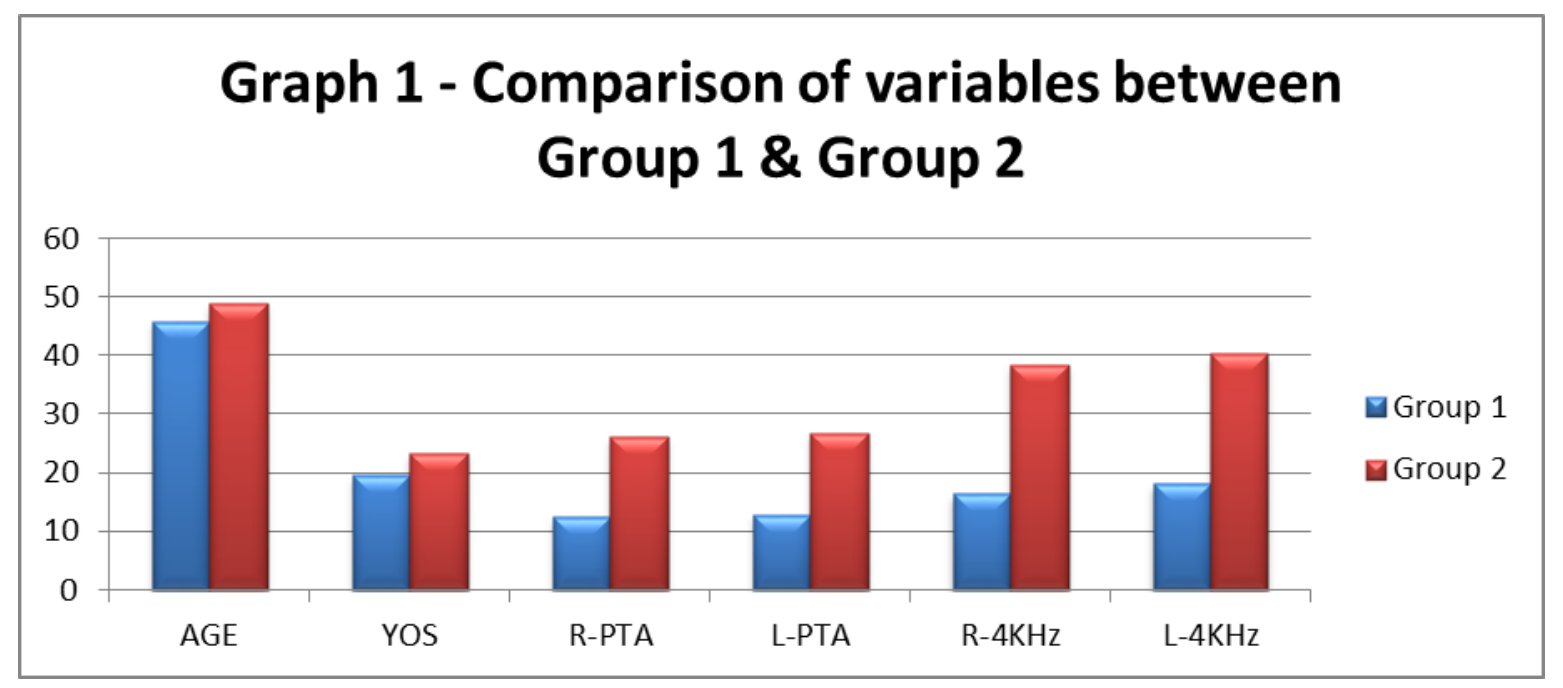

Table 1:-Comparison of variables between Group $1 \&$ Group 2

\begin{tabular}{|l|l|l|l|l|l|}
\hline Group Statistics & group & $\mathrm{N}$ & Mean & Std. Deviation & Std. Error Mean \\
\hline & 1 & 88 & 45.82 & 3.825 & .408 \\
\cline { 2 - 6 } AGE & 2 & 153 & 48.86 & 4.797 & .388 \\
\hline \multirow{3}{*}{ Years of service } & 1 & 88 & 19.58 & 4.255 & .454 \\
\cline { 2 - 6 } & 2 & 153 & 23.39 & 5.548 & .449 \\
\hline \multirow{2}{*}{ RPTA } & 1 & 88 & 12.46 & 1.992 & .212 \\
\cline { 2 - 6 } & 2 & 153 & 26.12 & 4.737 & .383 \\
\hline \multirow{3}{*}{ RPTA } & 1 & 88 & 12.79 & 1.984 & .211 \\
\cline { 2 - 6 } & 2 & 153 & 26.77 & 4.984 & .403 \\
\hline \multirow{2}{*}{ L4Khz } & 1 & 88 & 16.36 & 4.063 & .433 \\
\cline { 2 - 6 } & 2 & 153 & 38.40 & 9.295 & .751 \\
\cline { 2 - 6 } & 1 & 88 & 18.13 & 4.753 & .507 \\
\hline
\end{tabular}

From Table -1 and Graph - 1 it can be inferred that the mean age of police personnel in group 1 and group 2 were 45.82 and 48.86 respectively with a standard deviation of 3.8 and 4.8. The years of service also found to be more in the affected population when compared to the normal hearing police personnel in group 1. Hence it shows that as the years of service increases, the risk of hearing deficit also increases.

While comparing the pure tone averages (PTA) of Right ear and Left ear (RPTA \& LPTA) between both the groups, the affected group (Group 2) shows a significant increase in pure tone average values when compared to Group 1. Also, the mean PTA values of Group 2 is found to be 26.12 and 26.77 in Right ear and Left ear respectively, which indicates the presence of mild degree of hearing loss in both the ears.

The noise induced hearing loss component which can be correlated with the threshold and dip at $4000 \mathrm{~Hz}$ is also noted and average hearing threshold is estimated in both the groups. The results show that $4 \mathrm{KHz}$ threshold is more in Group 2 when compared to Group 1. The average threshold at $4000 \mathrm{~Hz}$ for Group 1 is $16.36 \mathrm{~dB}$ in Right ear and $18.13 \mathrm{~dB}$ in Left ear, whereas for Group 2, it is $38.40 \mathrm{~dB}$ in Right ear and $40.23 \mathrm{~dB}$ in Left ear, which shows a significant increase in thresholds among Group 2 individuals.

A comparison was also made within Group 2 individuals on Right \& Left ear Pure Tone Averages and 4 KHz thresholds. The results are shown in Table -2 and its graphical representation is depicted in Graph -2 .

Table - 2 shows the different degrees of hearing loss and NIHL component present in the Group 2 police personnel. From table -2 it can be inferred that upto moderate degree of hearing loss is present in both ears. Out of 153 police personnel, 43.8\% (67/153) had minimal hearing loss, 54.9\% (84/153) had mild hearing loss and 1.3\% (2/153) had 
moderate degree of hearing loss in Right ear. As well as, in Left ear, 35.94\% (55/153) had minimal hearing loss, $62.74 \%$ (96/153) had mild hearing loss and 1.3\% (2/153) had moderate hearing loss.

Table 2:-Comparison of Variables within Group 2

\begin{tabular}{|l|l|l|l|l|}
\hline & RPTA & LPTA & R4KHz & L4KHz \\
\hline Minimal & 67 & 55 & 16 & 6 \\
\hline Mild & 84 & 96 & 99 & 91 \\
\hline Moderate & 2 & 2 & 33 & 51 \\
\hline Mod. Severe & 0 & 0 & 3 & 4 \\
\hline Severe & 0 & 0 & 2 & 1 \\
\hline
\end{tabular}

The results from Table-2 and Graph - 2 also reveal a various degrees of hearing loss thresholds present in $4000 \mathrm{~Hz}$ at both ears. In Right ear, $10.45 \%$ ( 16/153) had minimal hearing loss, 64.7\%(99/153) had mild hearing loss, $21.57 \%(33 / 153)$ had moderate hearing loss, $1.96 \%$ (3/153) had moderately severe hearing loss and 1.3\%(2/153) had severe degree of hearing loss thresholds at $4000 \mathrm{~Hz}$. Whereas, in Left ear 3.92\% (6/153) had minimal hearing loss, $59.48 \%$ (91/153) had mild hearing loss, 33.3\%(51/153) had moderate hearing loss, 2.61\%(4/153) had moderately severe hearing loss and $0.65 \%(1 / 153)$ had severe hearing loss thresholds at $4 \mathrm{kHz}$. It can be clearly inferred from Graph -2 that majority of the Group -2 individuals are having mild degree hearing loss in both ears.

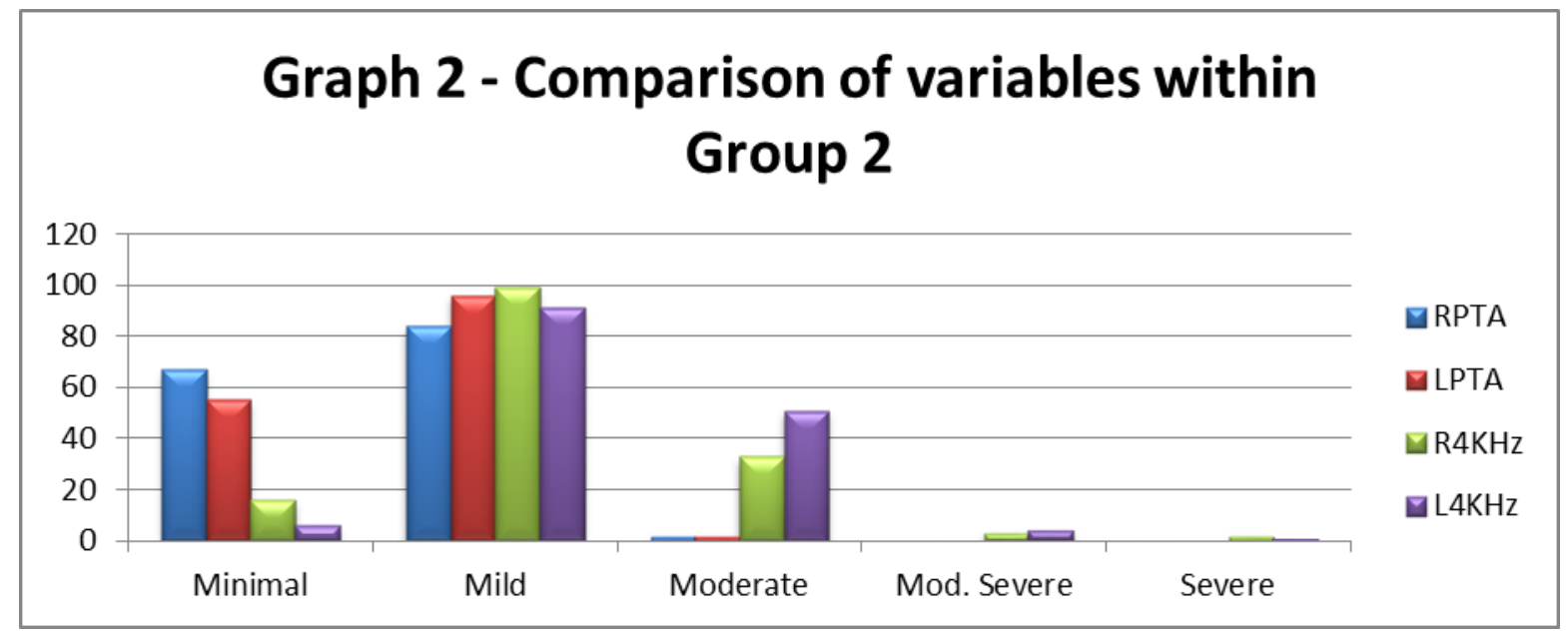

The present study also investigated the relation between years of service and degree hearing loss in the police personnel with hearing loss (i.e.) Group - 2. These results are shown in the following charts (chart 1 to chart 4).

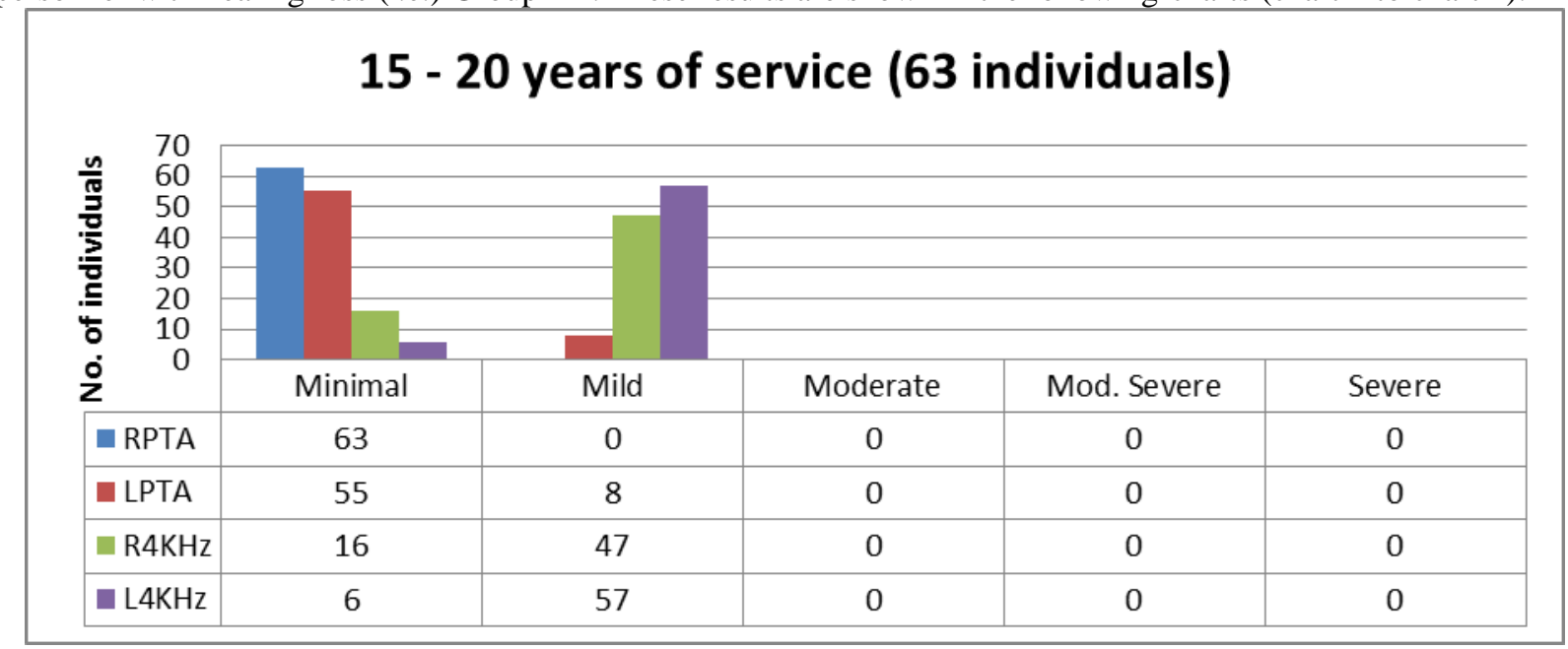

Chart 1:-Individuals affected with hearing loss in $15-20$ years of service 


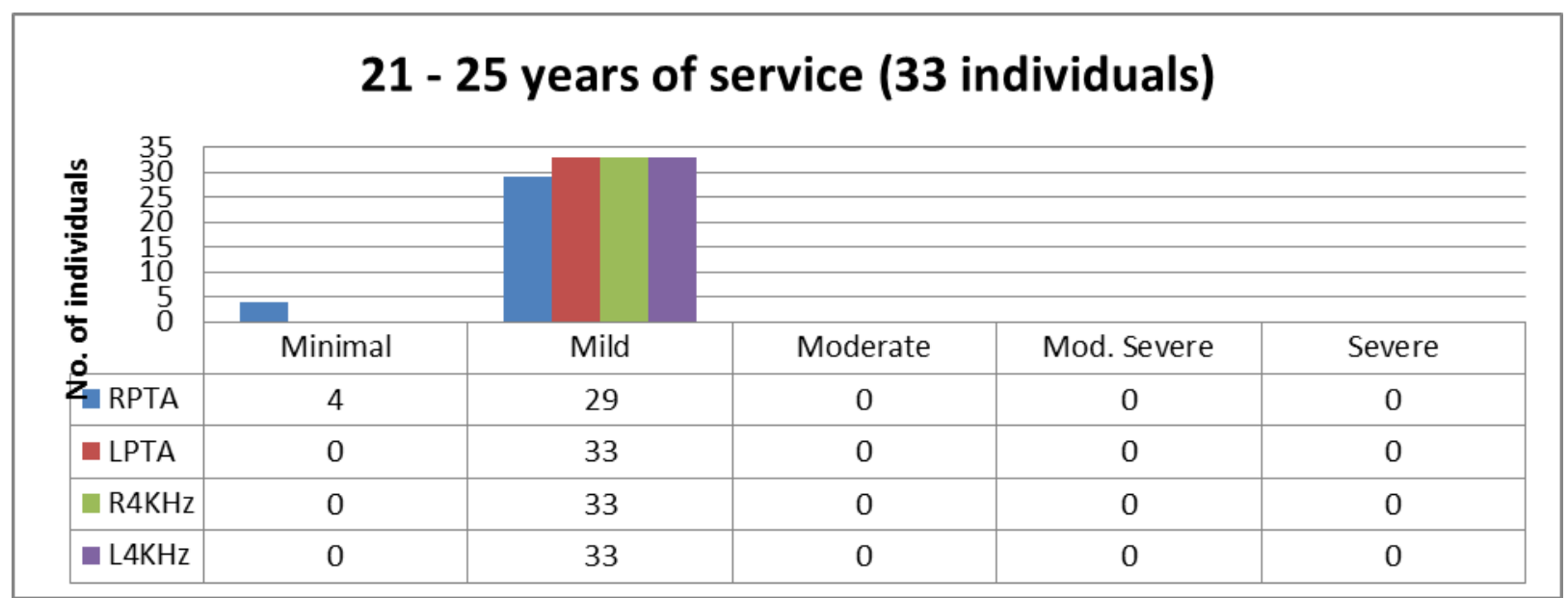

Chart 2:-Individuals affected with hearing loss in 21-25 years of service

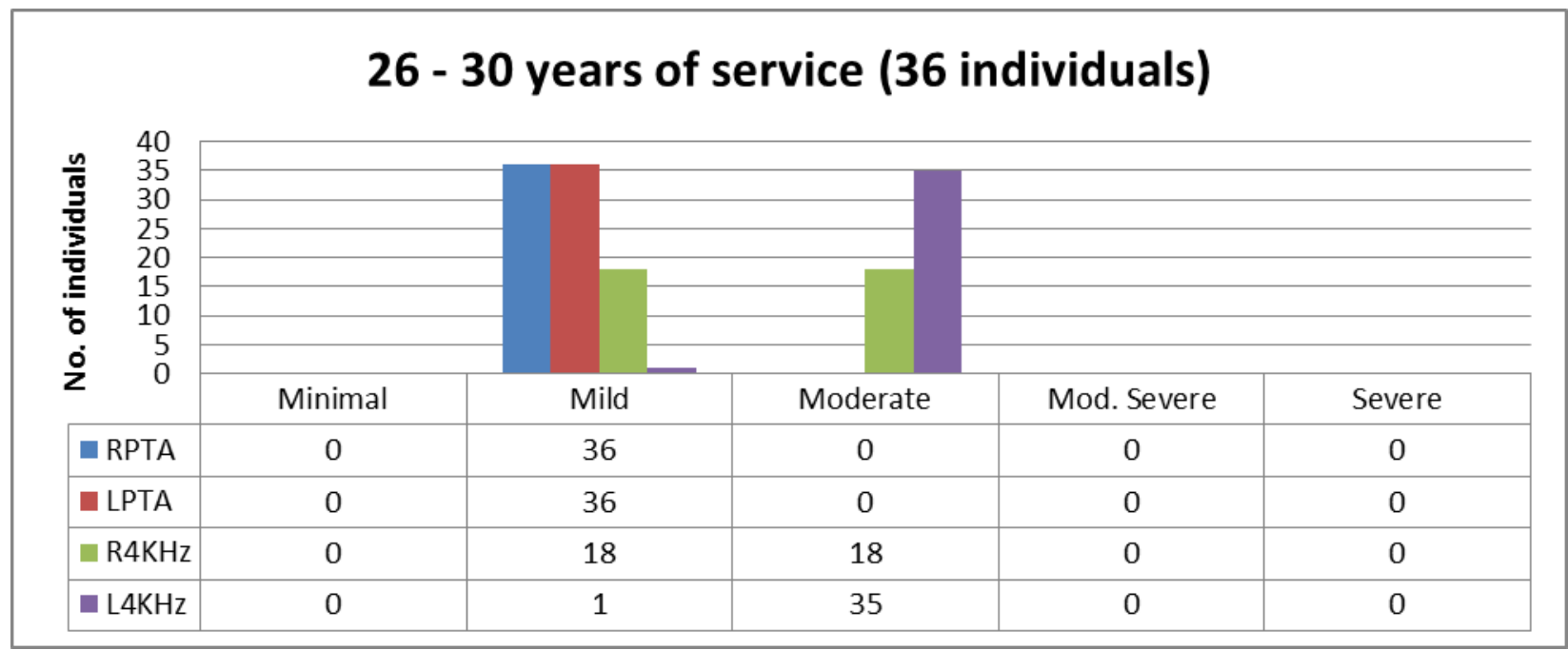

Chart 3:-Individuals affected with hearing loss in $26-30$ years of service

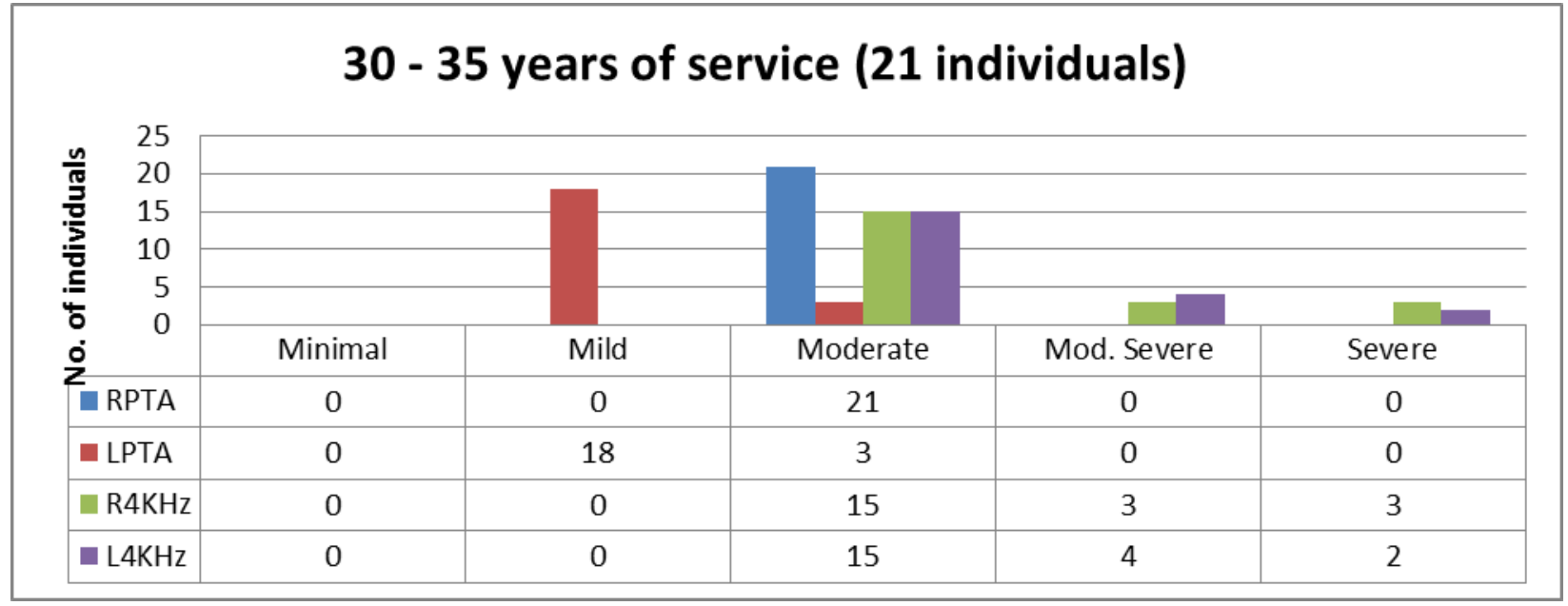

Chart 4:-Individuals affected with hearing loss in $30-35$ years of service 


\begin{tabular}{|c|c|c|c|c|c|c|c|c|}
\hline & & \multicolumn{7}{|c|}{ t-test for Equality of Means } \\
\hline & & \multirow[b]{2}{*}{$\mathrm{t}$} & \multirow[b]{2}{*}{ df } & \multirow[b]{2}{*}{$\begin{array}{l}\text { Sig. (2- } \\
\text { tailed) }\end{array}$} & \multirow[b]{2}{*}{$\begin{array}{l}\text { Mean } \\
\text { Difference }\end{array}$} & \multirow[b]{2}{*}{$\begin{array}{l}\text { Std. Error } \\
\text { Difference }\end{array}$} & \multicolumn{2}{|c|}{$\begin{array}{l}95 \% \text { Confidence Interval } \\
\text { of the Difference }\end{array}$} \\
\hline & & & & & & & Lower & Upper \\
\hline \multirow[t]{2}{*}{ AGE } & Group 1 & -5.093 & 239 & .000 & -3.045 & .598 & -4.222 & -1.867 \\
\hline & Group 2 & -5.410 & 214.925 & .000 & -3.045 & .563 & -4.154 & -1.935 \\
\hline \multirow[t]{2}{*}{ Sex } & Group 1 & 3.528 & 239 & .001 & .141 & .040 & .062 & .220 \\
\hline & Group 2 & 3.062 & 119.284 & .003 & .141 & .046 & .050 & .232 \\
\hline \multirow{2}{*}{$\begin{array}{l}\text { Year of } \\
\text { service }\end{array}$} & Group 1 & -5.561 & 239 & .000 & -3.806 & .684 & -5.154 & -2.458 \\
\hline & Group 2 & -5.966 & 219.937 & .000 & -3.806 & .638 & -5.063 & -2.549 \\
\hline \multirow[t]{2}{*}{ RPTA } & Group 1 & -25.76 & 239 & .000 & -13.666 & .530 & -14.711 & -12.621 \\
\hline & Group 2 & -31.21 & 223.012 & .000 & -13.666 & .438 & -14.529 & -12.803 \\
\hline \multirow{2}{*}{ LPTA } & Group 1 & -25.18 & 239 & .000 & -13.986 & .555 & -15.080 & -12.892 \\
\hline & Group 2 & -30.73 & 218.312 & .000 & -13.986 & .455 & -14.883 & -13.089 \\
\hline \multirow{2}{*}{ R4KHZ } & Group 1 & -21.09 & 239 & .000 & -22.035 & 1.045 & -24.093 & -19.977 \\
\hline & Group 2 & -25.40 & 226.162 & .000 & -22.035 & .867 & -23.744 & -20.326 \\
\hline \multirow[t]{2}{*}{ L4Khz } & Group 1 & -22.21 & 239 & .000 & -22.104 & .996 & -24.065 & -20.143 \\
\hline & Group 2 & -25.67 & 238.679 & .000 & -22.104 & .861 & -23.800 & -20.408 \\
\hline
\end{tabular}

The above charts (Chart 1 to Chart 4), shows the relationship between years of service of the police personnel and their degrees of hearing losses. As it could be seen from the above charts that with 15-20 years of service (Chart-1), majority of the population had minimal and mild hearing loss, with 21-25 years of service (Chart-2), many of them fall into mild hearing loss category, with 26-30 years of service (Chart-3), the individuals had mild and moderate degree of hearing loss and with more than 30 years of service (Chart-4), the individuals hearing loss degree shifted to moderate, moderately severe and severe categories. This reveals that, as the years of service in the police individuals increases, their degree of hearing loss also increased.

All the variables were again statistically analyzed with t-test, which showed a significant difference between Group 1 and Group 2. Also there was a significant association with NIHL and years of service where $\mathrm{p}=0.00$

\section{Discussion:-}

Occupation induced hearing loss is well documented in various work environments such as industries, persons working with machineries, musicians, traffic noise etc. However, the effects of noise exposure are not much noticed among the police personnel, who are also at high risk category for the Noise induced hearing loss. The results of the present research showed that $63.48 \%$ of the study population had significant hearing loss. The results of the current study are similar to the findings of previous studies, where the prevalence of NIHL among Pune traffic police in India is $81.2 \%, 66.4 \%$ among traffic police personnel in Kathmandu city and $84 \%$ among traffic police in Jalgaon Urban Centre in India.

The results of the present study also show a hearing threshold elevation as the years of service increases which is again supported by previous studies $(4-7)$. The degree of hearing loss differs from individual to individual and the susceptibility may be due to difference in mass and shape of ossicles, difference between area of tympanic membrane and oval window, chemical characteristics of endolymph, size and tension of middle ear muscles and blood supply to cochlea (Boettcher, 1993). The hearing sensitivity in noisy environments deteriorates three times faster than by ageing process $(4,5)$. The present study also reports an increase in threshold and a dip at $4000 \mathrm{~Hz}$ with increase in years of service. This can be correlated with the effects of noise.

In the early stages of NIHL, the speech frequencies are less affected and the patients have a very few symptoms and hence they are usually unaware of the deleterious effects of sound $(9,10)$. At this stage, frequency area $4-6 \mathrm{KHz}$ is usually affected first with maximum at $4 \mathrm{KHz}$ (11). Any level of NIHL may muffle high frequency sounds such as whistles or buzzers and may result in difficulty discriminating speech consonant sounds such as those in the words fish and fist, particularly in the noisy environments with background noise, many voices or room reverberation (10, 12). A similar speech understanding difficulty was experienced by the subjects in the present in the noisy 
environments. In the present study few subjects with more than 25 years of service also reported that they could hear the conversations in the noisy environment, but it's difficult to understand certain words occasionally.

The strength of the present study is the data size with number of personnel having similar work environment and job, fact that all the police personnel were medically and audiologically fit during the time they joined their duty. However larger study would be desirable for more precise risk estimates. In our study we are unable to measure the exact level of noise exposure, because it was not feasible to conduct environment noise measurement during gunfire practice and walkie talkie conversation noise level, owing to administrative reasons. Also, longitudinal studies can be conducted among such personnel in order to know the precise effects of noise. Otoacoustic emissions are also suggested as a tool in the future researches.

\section{Conclusion:-}

The present study showed that even the police personnel are at risk for Noise Induced Hearing Loss due to their nature of job and work environment. Study has also proven that with increase in years of service the hearing thresholds also elevates. Hence in order to prevent the hearing loss, the police personnel are also advised to use some Ear Protective Devices during the times of noise exposure. And they are also recommended to undergo periodic audiological evaluations.

\section{References:-}

1. D Bruce Kirchner, Col. Eric Evenson, Robert A. Dobie, Peter Rabinowitz, James Crawford, Richard Kopke and Warner Hudson. "Occupational Noise - Induced Hearing Loss - ACOEM Task Force on Occupational Hearing Loss". ACOEM Guidance Statement.

2. Francois-Xavier Lesage, Nicolas Jovenin, Frederic Deschamps and Samuel Vincent. (2009). "Noise-induced hearing loss in French police officers". Journal of Occupational Medicine. July; 59: 483 - 486.

3. Hanssen SQ, Thorud E, Aasand G (1979). "Noise induced hearing loss and the comprehension of speech in noise". ActaOtolaryngol (suppl); 360: 90 - 95.

4. Hong O S (2005). "Hearing loss among operating engineers in American construction industry". International Archives of Occupation and Environment Health; 78: 565 - 574.

5. KyawN.Win, Nayake B.P. Ballala, Min Z. Lwin and Alice Lai (2015). "Noise induced hearing loss in the police force". Journal of Safe Health Work. June 6(2):134 - 138.

6. Md. Haider Y, Ahmmad T, Manjur R, Huq AHMZ, Abdulla M (2008). "Noise Induced hearing loss among the textile industry workers". Bangladesh Journal of Otorhinolaryngology. 14(2): 39 - 45.

7. Michael Stewart. "Recreational Firearm Noise Exposure". Available at http://www.asha.org/public/hearing/Recreational-Firearm-Noise-Exposure/

8. Rop I, Raber A, Fscher GH (1979). "'Study of hearing losses of industrial workers with occupational noise exposure, using statistical methods for the analysis of qualitative data". Audiology; 18: 181 - 196.

9. Shreshtha I, Shreshtha BL, Pokharel M, Amatya RCM and Karki DR (2011). "Prevalence of Noise induced hearing loss among traffic police personnel of Kathmandu metropolitan city". Kathmandu University Medical Journal. 36(4): $274-278$.

10. V K Singh and A K Mehta (1999). "Prevalence of occupational noise induced hearing loss amongst traffic police personnel”. Indian Journal of Otolaryngology Head Neck Surgery. Apr 51(2): 23 - 26.

11. Sivasubramanian R, Krithiga S K, Dhivya S, Keerthinarayana S (2014). "Assessment of Traffic noise and annoyance response in madurai city". International Journal of Advanced Technology in Engineering and Science. Vol. 20, Issue 12, Dec 2012: 646-653.

12. SubrotoS.Nandi and Sarang V. Dhatrak. (2008). "Occupational noise - induced hearing loss in india". Indian Journal of Occupation Environmental Medicine. Aug 12(2): 53-56. 